\title{
Correction to: Manually scaling ionograms measured by Icheon and Jeju ionosondes over a 2-year period (2017-2018)
}

\author{
Sangwoo Lee ${ }^{1} \cdot$ Yong Ha Kim ${ }^{1}$ (D) Se-Heon Jeong ${ }^{1} \cdot$ Young-Sil Kwak $^{2} \cdot$ Jong-Yeon Yun $^{3}$
}

Published online: 4 August 2021

(c) The Korean Physical Society 2021

Correction to: Journal of the Korean Physical Society https://doi.org/10.1007/s40042-021-00174-3

Due to an unfortunate oversight the third author's name has been misspelt. It should read Se-Heon Jeong

The original article has been corrected.

Publisher's Note Springer Nature remains neutral with regard to jurisdictional claims in published maps and institutional affiliations.

The original article can be found online at https://doi.org/10.1007/ s40042-021-00174-3.

Yong Ha Kim

yhkim@cnu.ac.kr

1 Department of Astronomy, Space Science and Geology, Chungnam National University (CNU), Daejeon 34134, Korea

2 Korea Astronomy and Space Science Institute (KASI), Daejeon 34055, Korea

3 Korea Space Weather Center (KSWC), Jeju 695-922, Korea 